\title{
The Personality Emotional Structure In Interior Design
}

\author{
Jing Zeng / Keyue Duan \\ (College of Forestry, Sichuan Agricultural University, Wenjiang 611130,China)
}

\begin{abstract}
In today's word, people on indoor function and aesthetic demand to meet at the same time, more and more pursuit space design build atmosphere of psychological sense of fit and satisfaction. As interior design elements such as form, color, texture, light, they can make the space character visualization, and mental feeling transformation of environment influence. This paper discusses and finds out the mapping of character emotion structure in interior design and its adverse effect.
\end{abstract}

Key words: Emotion; Consciousness; Emotional; Interior design; color

\section{The meaning and characteristics of Emotional Structure}

Emotion is refers to the person of a general term for a series of subjective cognitive experience, a variety of feelings, thoughts and behavior of comprehensive psychological reaction and physiological state, is a form of human reaction. And emotion is not only a response to an objective thing, but also to a certain kind of association between the subject and the object. Emotions of three elements respectively refers to the physical, emotional and emotional experience, because the mood has a unique subjective experience and external behavior, they, together with the physiological basis is seen as a mood of the three elements.

The study of emotion has been in modern times in western culture. Contemporary American book The Psychology of Emotion, Mind: An Essay on Human Feeling, Feeling and Form: A Theory of Art written by Susanne K.Langer, On understanding emotion written by Norman K. Denzin, the emotional phenomenology, by well-known German philosopher, Max Scheler, all these works from different angles expounds the definition of emotion, and never provided the emotional connotation are studied and discussed.

\section{The significance of using the personality emotional structure in interior design}

H.Gene Blocker in his book Aesthetis Design Art Education put forward: "emotional or spiritual content can be in sound, shape, image and line and color constitutes the physical structure of the embodiment of the art." For a long time, people have also been able to express their emotions in the form of art, through artistic design. As one of the most important architects in the 20th century and is known as "flagman" of modern architecture of le corbusier thought of building doors and Windows in indoor space layout design could cause different emotional state, way of door opening and closing the space of the light change back pulling people happy or sad, such considerations to emotional structure detail design is the embodiment of the emotional design. Donald Arthur Norman, in his book Emotional Design, from three aspects to elaborate the importance of emotional design: (1) the instinctive level, refers to the product itself brings to the consumers of sensory stimulation, the 
stimulation can be quickly on safety and danger, good or bad, such as judgment, and then to the movement system signal. (2) the behavior level, the consumer can gain emotion in the use of the product. (3) emotional reflection, it is under the action of instinct level and behavior level, the customer psychology of emotion, meaning and humanity, and other comprehensive emotional factors together.

In regarding to the application of emotional design, masters also pour into their creativity and imagination, the Finnish architect Aalto advocate building to human feeling, for example, he thinks that architectural design should be "in order to solve social and psychological demand as the goal", at the completion of the architectural design in the process of the most important thing is to find a reasonable way of breakthrough technology to design in the field of emotion psychology. Frank Lloyd Wright, the American representative of The Arts \& Crafts Movement, also said: "architecture is a great feeling of human beings in the world they build themselves." His works Willitts House, Fallingwater House, Guggenheim Museum and Robie House can let a person experience Wright for emotional design in the pursuit of "the milk of human kindness". Also for example designed by Le Corbusier La Chapelle de Ronchamp, the change of its internal space brings the profound aesthetic mood like misty, wall hole projection light effect also to the people come to pilgrimage to considerable perturbation spirituality, La Chapelle de Ronchamp marked the change of Le Corbusier style, in its design, Le Corbusier out of rationalism, turned to the romantic and mysticism, the use of special architectural form to express special emotional characteristics.

In daily life, people are always reflects the person's mood psychological space environment, artificial space sequence structure in space, the choice of topic selection of colors and furniture furnishings are removed to satisfy people basic life functions, parcel full of aesthetic, imagination, emotion and other abstract spiritual elements, which makes the users in the interior space and environment atmosphere produces implicit connection of thinking, to gain a profound emotional experience and emotional resonance. So when be being designed indoors, the designer can guide and use of emotional elements to change and improve the living space, to promote the scientization of interior design and humanization, make indoor design development in the direction of emotion, of course, it also must be a focus on the process of scientific and rigour, induced by external emotions and internal emotional design to improve the user experience, the use of indoor material for internal emotional design promote sense of comfort, the design of second color also can affect the space integral atmosphere rendering and build.

\section{The embodiment of the personality emotional structure in interior design}

(1) The character and drama set in the films directed by Wes Anderson blend with interior design

Wes Anderson is now the United States the new generation of directors in one of the most popular attention, his personal style, the most interesting and creative, the mini set and control of the photography light still feast for the eyes, and in terms of color aesthetic attainments deep. His movies are always filled with moving long, refined decoration, gorgeous scenery, cold humor, amazing character relationship, 
plus Randall Poster and Alexandre Desplat soundtrack, completely is a wonderful audio-visual feast.

Everyone who has seen his movies impressed by the high saturation of warm color, especially in The Grand Budapest Hotel, also known as textbooks general palette. One of the most classic scene is two young lovers are in bullets, but still immersed in the background MENDL 'S sweet of indoor environment, the focus of the whole and interior design color based on powder pink and blue, two kinds of color is tonal and consistent, high saturation is lightness, overall a palpitating emanating, calm and pure and fresh and sweet taste, interior design in the form of rest of light adjustment plot rhythm.

In the other early work of Wes Anderson, the relationship between interior design and character drama was also well integrated. In Moonrise Kingdom,which leading roles of a fairy tale journey are children, including length less indoor scene also have fine features, interior design in the case of to match the movie overall tone, with a group of army green, the complementary color images of empty rose pink and blue color, pure and fresh and do not break lively, virtually amplifies the children fairy warm between optimism and naivety. The Life Aquatic with Steve Zissou to the inside of the submarine in the indoor environment with a Mustard Yellow, Bright Orange, and a series of gray neutral colors, three colors of the two kinds of similar to each other, another contrast from them, so that the separation of complementary color collocation makes the picture endowed with impact, also with the main character of The Old Man and the Sea crisis struggle with hardship in bad mood. The Royal Tenenbaums, the film with the warmth of family, domestic outfit design Wes Anderson chose a lot makes space emotion softening of Powdery Pink or Macaron Pink, which is the cigar smoke enveloped the characters in this one space after relaxes and cured, enjoy a moment of peace. In the amazing animation The Fantastic Mr. Fox, the director is to approximate color more radical embodying the fox in the tree house details, with brown color to dress up the warmth of family life.

\section{(2) Design Without Thought in Japan}

Without Thought is a concept originated from Japanese industrial design master Naoto Fukasawa, it refers to the unconscious activities into the visible items, therefore is also called Design Without Thought. Naoto Fukasawa once said, "when do design for an item, the first thing that went through my mind, everyone can feel that, but may not be aware of what is a good thing, my job is to take such a collective unconscious thing with." For example, the slotted umbrella stand design is designed for the top of the umbrella groove convenient people subconsciously to hang bags, and Naoto Fukasawa design of tea bag, he thinks that the action of tea bag and puppet show performances have the same effect, so the tea bag design for the form of muppet, the design is ingenious depend on " design in the part of subconscious", his works full of humanities concern because he attention to every single details and emotion.

These seemingly meaningless subconscious actions with fresh creative technique solves the people in actual life inconvenient, the Unconscious is actually the life experience in the design of the unconscious after summarizing the product of conscious, it comes from designers carefully detect and attention to the design of daily 
life, as another famous Japanese graphic designer Kenya Hara said: "life is the most cruel, only suitable for the implements of the life, can be handed down from generation to generation, from a long time." Daily design is one of the most common contact every day, but actually many times we have been ignored, good design may not necessarily seize person eyeball anywhere surprise design, suitable for life demand for meeting the needs of daily function design, the people are aware of its existence, in use process may be unconscious design significance.

There are some thing in common between the principle of design without thought in Japan and the Subconsciousness Theory suggested by Sigmund Freud. Freud explore in the field of human spirit analysis to define "unconscious" is repressed under conscious and subconscious psychological activity has not been realized. Extension is also observed that the unconscious design on the application of interior design is also more is a kind of emotional design, unconscious design concept "human touch" is also in the indoor environment on human care and the psychological activity guidance to adjust the mood structure control.

\section{(3) The influence of green plants to emotion}

In interior design, the emotional bond between people and green plants becoming stronger, and now the plant is also become the symbol of a better life in the elements of interior design. It's easy to link up the plant with the pastoral scenery and anti-urban life, so it is instinct to enjoy immersed in the living environment of surrounded by beautiful plants, as scientific fields such as emotional ecology also very concerned about this kind of subtle emotional connection between human and nature, and on the other hand, in the study of plant nerve biology also explore to the plant in does not have under the condition of the traditional sense of the nervous system can also have the ability to convey information.

Many interior design works chose the interaction between people and indoor green plant as the theme, such as Dossofiorito studio in Vienna, the meaning of Dossofiorito is the hills of flowers, the designer Gianluca Giabardo and Livia Rossi saw this strange words in a neon lights from an old yard, so they chose it to be the name of studio, the studio's predecessor is a garage, now the full of green plants design is often mistaken for a flower shop. Many interior designs of restaurant also lock on the green plant display, like Väkst, a restaurant in Copenhagen , which serves organic vegetables. The interior design is set like a greenhouse, it choose a large number of green plants and natural materials to create a vivid, vital environment. The stair in Väkst interplanting green plant, the outline to the square of Angle steel structure located in the central area which is similar to the cultivation of greenhouses. The bottom of steel frame decorated with plants in pots, the purpose is to connect the main dining area in the first floor and partial basement. Green plants display can soften the space, make them full of vitality, create a good repast atmosphere for customers. Plant can purify space environment and provide a beauty of nature space for diner artistic conception.

From the fusion whit interior design and plants, we can see that the core is also the interaction between human and plant. In daily life, we are getting along with the plant model may also experience the gaze, care, joy and sorrow mood changes, such 
as the display of green plant is pulling the environment human mood fluctuations, therefore in the process of the interior design of stylist should plant elements for the reasonable use.

\section{(4) Baker Miller Pink}

Baker Miller Pink is the only color that can be scientifically proven to calm moods and suppress appetite. In the late 1960s, Alexander Schauss, who now operates the American Institute for Biosocial Research in Tacoma, Washington, did studies on psychological and physiological responses to the color pink. Schauss had read studies by the Swiss psychiatrist Max Luscher, who believed that color preferences provided clues about one's personality. Luscher noticed that color preferences shifted according to psychological and physiological fluctuations in his patients. He theorized that one's color choices reflect corresponding changes in the endocrine system, which produces hormones. In early tests in 1978, he discovered that a particular shade of pink had the most profound effect. He labeled this tone of pink P-618. Schauss noted that by merely staring at an $18 \times$ 24inch card printed with this color, especially after exercising, there would result "a marked effect on lowering the heart rate, pulse and respiration as compared to other colors."

In 1979, Schauss managed to convince the directors of a Naval correctional institute in Seattle, Washington to paint some prison confinement cells pink in order to determine the effects this might have on prisoners. Schauss named the color after the Naval correctional institute directors, Baker and Miller. Baker-Miller Pink is now the official name of the paint whose color has the following RGB code: R: 255, G: 145, B: 175. At the correctional facility, the rates of assault before and after the interior was painted pink were monitored. According to the Navy's report, "Since the initiation of this procedure on 1 March 1979, there have been no incidents of erratic or hostile behavior during the initial phase of confinement". Only fifteen minutes of exposure was enough to ensure that the potential for violent or aggressive behavior had been reduced, the report observed.

Since then many hospitals and disciplinary institution to Baker Miller Pink use, such as Santa Clara County jail, California VA psychiatric hospital, San Bernardino youth clinic, etc., now there are some sports brands like Vollebak design with Baker Miller Pink as the theme color of the hoodie is used to reduce anxiety. By Baker Miller Pink in use can be found in the design of indoor color effect on the regulation of human physiological and psychological function, in the psychological function of mental patients, cognitive function, social function recovery in the process, can be applied to the design of the treatment environment of this kind of subtle color treatment method, in the form of used to upgrade the quality of life of patients. In the environment of our daily life, we should also design the interior environment based on color science and psychology.

\section{Conclusion}

Humans are sensitive animals, who devote emotion to the environment they live. They pursue comfortable environment to live, at the same time, they also care about beauty and pay attention to the thing like a sense of belongs and kindness the beauty brings. This paper probes the personality emotional structure in the interior design is 
widely used, also affect interior design in the adverse effect of emotional psychology to find many aspects.

Designers today are constantly making breakthroughs from the emotional design and humanization design to achieve the rational use of materials in the design of beautiful, science and technology of visual comfort, thus designed to satisfy people physiological and psychological two aspects of function of pleasant working environment. On the other hand, for some special people who need psychological treatment, we should provide them a personality matching habitable environment with scientific interior design purposefully.

\section{Acknowledgments}

Key Laboratory of Wood Industry and Furniture Engineering of Sichuan Provincial C olleges and Universities

\section{References}

[1] Donald Arthur Norman.Emotional Design [M]2005.

[2] Kenya Hara.Designing Design [M].Lars Mullre Publishers,2015.

[3]Zhao Ying.The Importance Of Emotion In Interior Design [D] Inner Mongolia:Inner Mongolia Normal University,2009.

[4] James E. Gilliam and David Unruh. The Effects of Baker-Miller Pink on Biological, Physical and Cognitive Behaviour[J]. Journal of Orthomolecular Medicine Vol. 3. No. 4, 1988.

[5]. Yuxiaoming. The application of ornamental plants in interior design [J]. Modern gardening, 2016, (9) : 145-146. 